\title{
Espinheira-santa: do extrativismo à produção sustentável
}

\author{
Jéssica Soares GARCIA¹, Clovis José Fernandes OLIVEIRA JR ${ }^{1 *}$ \\ ${ }^{1}$ Instituto de Botânica, Secretaria do Meio Ambiente, São Paulo, SP, Brasil. \\ *E-mail: floraacao@gmail.com
}

(ORCID: 0000-0001-8044-0820; 0000-0003-2207-6287)

\begin{abstract}
Recebido em 23/04/2021; Aceito em 10/09/2021; Publicado em xx/09/2021.
RESUMO: O uso tradicional de espécies nativas para fins terapêuticos apresenta benefícios diretos e imediatos para distintas populações locais, seja pelo cuidado com a saúde ou pela possibilidade de produção e geração de renda. Porém, podem colaborar com a degradação dos ecossistemas, pelo extrativismo e superexploração, que têm colaborado com o avanço do desequilíbrio ecológico. Deste modo, o objetivo desse estudo foi utilizar a Maytenus ilicifolia para exemplificar o que ocorre em relação à exploração e uso de plantas medicinais no Brasil. O estudo foi conduzido a partir da literatura científica, sendo a busca realizada nas plataformas Scielo, ResearchGate, Scoppus, Web-of-Science e Google Acadêmico. As palavras espinheira-santa e Maytenus ilicifolia foram utilizadas nas buscas. Foram selecionados os artigos que abordassem os aspectos: botânica, ecologia, etnobotânica, fitoquímica, fitotecnia e adulterações. Como resultados, verificamos um grande número de publicações sobre fitoquímica, que a espécie sofre com extrativismo e falsificações, e que o manejo em agroecossistemas é ainda incipiente. Concluímos que são necessários incentivos em políticas públicas para pesquisas, produção e divulgação da espécie. Sua inserção em cadeias produtivas configura a sua conservação on farm, possibilitando um passo efetivo para conservação e preservação da espécie.

Palavras-chave: agroecologia; conservação on farm; Maytenus ilicifolia; sociobiodiversidade; agricultura familiar.
\end{abstract}

\section{Espinheira-santa: from extractivism to sustainable production}

ABSTRACT: The traditional use of native species for therapeutic purposes has direct and immediate benefits
for different local populations, whether for health care or the possibility of production and income generation.
However, they can collaborate with the degradation of ecosystems, through extractivism and overexploitation,
which have collaborated with the advancement of ecological imbalance. Thus, the objective of this study was
to use Maytenus ilicifolia to exemplify what happens in relation to the exploration and use of medicinal plants in
Brazil. The study was conducted based on the scientific literature, and the search was carried out on the Scielo,
Research-Gate, Scoppus, Web-of-Science and Google Scholar platforms. The words espinheira-santa and
Maytenus ilicifolia were used in the searches. Articles that addressed the following aspects were selected: botany,
ecology, ethnobotany, phytochemistry, phytotechnics and adulterations. As a result, we verified many
publications on phytochemistry, that the species suffers from extractivism and forgery, and that management
in agroecosystems is still incipient. We conclude that public policy incentives are needed for research,
production and dissemination of the species. Its insertion in production chains configures its conservation on
farm, enabling an effective step towards conservation and preservation of the species.
Keywords: agroecology; conservation on farm; Maytenus ilicifolia; sociobiodiversity; family farming.

\section{INTRODUÇÃO}

O Brasil é conhecido como detentor de uma das maiores biodiversidades do planeta, destacando-se um grande número de espécies e endemismos vegetais. Porém, estimase que entre 10 e $20 \%$ das espécies permaneçam desconhecidas (ULLOA et al., 2017; GASPER et al., 2020), sobretudo como potencial para produção e uso sustentável de seus elementos (OLIVEIRA JR; CABREIRA, 2012; MATADIUA et al., 2014; WOOD et al., 2015; GBEDOMON et al., 2017; UDAWATTA et al., 2019; HARTWIG et al., 2020). Tratando-se das plantas, pode-se dizer ainda que a vegetação é parte integrante da paisagem e serve como indicador da qualidade do ambiente, seu conjunto contribui para serviços ecossistêmicos, que são imprescindíveis para o bem-estar da humanidade, classificados em provisão, regulação, culturais e suporte (HALL et al., 2011; MORENO et al., 2018).
A diversidade no país contempla de 15 a $20 \%$ de toda biodiversidade mundial, segundo estimativas da Convenção da Diversidade Biológica (CDB, s/d). Reconhece-se que milhares de espécies são utilizadas por comunidades indígenas, populações tradicionais e camponeses brasileiros, e todo esse saber diminui o tempo de bioprospecção, isto é, desenvolvimento de pesquisa para a procura de fármacos novos (BARREIRO; BOLZANI, 2009).

De modo geral, as atividades humanas afetam as paisagens e as comunidades vegetais, alterando positivamente ou negativamente sua evolução e inter-relacionamentos (ANDERSON et al., 2020). Uma das formas de entender esse processo de correlações humanas com a natureza é a utilização dos conhecimentos da etnobotânica, que se alinham perfeitamente com aspectos culturais e ambientais (ALBUQUERQUE et al., 2008; SILVA et al. 2020), 
buscando e levando informações de relevância para as comunidades estudadas, contribuindo para a melhoria de qualidade de vida local (MEDEIROS et al., 2011; SILVA et al. 2020). Sua origem é antiga, assim como sua prática, e muitos cientistas reconhecem como ela auxilia no desenvolvimento dos povos (ALBUQUERQUE et al., 2008; MEDEIROS et al., 2011). Assim, em face à crise ambiental que presenciamos, é de suma importância que possamos analisar o desenvolvimento humano sem deixar de lado a conservação de ecossistemas naturais e a promoção de serviços ambientais e ecossistêmicos (BROOKS et al., 2006; TELLO; CASTILHO, 2013; LUEDLING et al., 2014; ANDERSON et al., 2020; STEENBOCK et al., 2020).

A bioprospecção tem como definição a investigação da biodiversidade para geração de novos produtos e processos, hoje já denominado cadeias produtivas da sociobiodiversidade (LIMA et al., 2017). E o uso da sociobiodiversidade tem sido apontado como enorme fonte de possibilidades para o uso sustentável da flora brasileira (OLIVEIRA JR; CABREIRA, 2012; DIAS et al., 2014; MATADIUA et al., 2014; LIMA et al., 2017; OLIVEIRA JR et al., 2018). Estes produtos se encontram em todo território brasileiro, sendo derivados da biodiversidade local e desenvolvidos pela cultura dos povos da região, muitas vezes ainda apresentados em formas artesanais (LIMA et al., 2017; HARTWIG et al., 2020). No entanto, as populações tradicionais devem ser respeitadas quanto aos seus direitos e conhecimentos, e qualquer tipo de utilização comercial de seus saberes deve ser partilhado corretamente, visando a participação e reconhecimento desses indivíduos no desenvolvimento de processos e produtos derivados da sociobiodiversidade (AZEVEDO, 2005; OLIVEIRA JR et al., 2012).

Consideramos ainda que muitas plantas medicinais vêm sendo exploradas ainda de forma extrativista, potencializando riscos de extinção (FERNANDES et al., 2013). Desta forma, o manejo dos recursos naturais para a produção sustentável de bens e serviços depende da disseminação de informações sobre o uso e sua importância socioeconômica. Nesta direção, os sistemas agroflorestais, os policultivos e os sistemas agroecológicos já vêm sendo apontados como formas mais sustentáveis de produção agrícola, e caracterizam o local ideal para produção destas espécies nativas (JOSE, 2012; MARTIN; ISAAC, 2015; STEENBOCK et al., 2020).

Assim, o estudo objetivou realizar um levantamento bibliográfico da espécie Maytenus ilicifolia Mart. ex. Reissek (espinheira-santa), através da análise de sua cadeia produtiva, por considerar - os aspectos botânica e ecologia, etnobotânica, fitoquímica, fitotecnia e adulterações. Este estudo pretende contribuir com a discussão sobre o potencial uso econômico das espécies medicinais nativas, bem como divulgar informações para estimular o desenvolvimento das cadeias produtivas da sociobiodiversidade, propondo maneiras para colaborar com a promoção do uso sustentável e com a conservação on farm em agroecossistemas sustentáveis.

\section{MATERIAL E MÉTODOS}

Esta pesquisa se propõe a promover uma análise exploratória a respeito da cadeia produtiva da espinheirasanta, apontando lacunas e possibilidades de aprofundamento de novos estudos. O trabalho foi desenvolvido a partir da literatura científica por meio de buscas de trabalhos que abordassem conhecimentos sobre a espinheira-santa. Para realizar este levantamento foram utilizadas as plataformas Scielo (https://www.scielo.org/pt/), Scoppus (https://www.elsevier.com/pt-br/solutions/scopus), Webof-Science (https://www.webofscience.com), Google Acadêmico (https://scholar.google.com.br/) e Research Gate (https://www.researchgate.net/). As palavras-chaves "Maytenus ilicifolia" e "espinheira-santa" foram escolhidas para realizar as pesquisas nas plataformas.

Os artigos passaram por uma leitura prévia do resumo, os fatores de inclusão foram que abordassem os temas botânica, ecologia, etnobotânica, fitoquímica, fitotecnia e/ou adulterações, sendo excluídos os trabalhos que não apresentassem nenhuma dessas abordagens. No total, foram selecionados 67 artigos sobre a espinheira-santa que possuem informações relevantes para o objetivo deste estudo, sendo descartados aqueles que estavam foram do contexto selecionado. Outros artigos, constantes das referências bibliográficas dos trabalhos alcançados, se pertinentes, também foram incluídos. Para a análise e encadeamento das ideias, eles foram divididos por temas: Botânica e Ecologia, Etnobotânica, Fitoquímica (composição química, comprovações científicas e toxicologia), Fitotecnia (produção, manejo e produtividade) e Adulterações (Tabela 1).

Tabela 1. Número de publicações sobre Maytenus ilicifolia utilizados neste estudo por temas abordados.

Table 1. Number of publications on Maytenus ilicifolia used in this study by topics covered.

\begin{tabular}{lc}
\hline \multicolumn{1}{c}{ Temas } & Número de artigos \\
\hline Botânica e Ecologia & 8 \\
Etnobotânica & 9 \\
Fitoquímica & 36 \\
Fitotecnia & 19 \\
Adulterações & 12 \\
\hline
\end{tabular}

Obs.: No total foram utilizados 67 artigos. A somatória dos artigos é maior que este valor, pois muitos artigos abordaram mais de um tema.

\section{REVISÃO}

\subsection{Botânica e Ecologia}

A Maytenus ilicifolia Mart. ex Reissek é uma planta nativa, porém não endêmica do Brasil que pertence à família Celastraceae (Flora do Brasil, 2020). O gênero Maytenus é o maior e mais diverso, com 200 espécies, dentre elas, 76 encontradas no Brasil. A espécie Maytenus ilicifolia predomina nos estados da região Sul do Brasil e nos países vizinhos Paraguai e Uruguai (RADOMSKI; BULL, 2010), mas também está presente nas regiões Sudeste, Nordeste e Centro Oeste (Figura 1), porém, com menor frequência.

Seu nicho ecológico encontra-se nas matas ciliares e subbosques no interior de matas nativas, onde o solo se apresenta rico em matéria orgânica e úmido (MAGALHÃES, 2002; LORENZI; MATOS, 2008). Como arbusto, sua altura mínima na fase adulta é de 1 a $2 \mathrm{~m}$, podendo, entretanto, chegar a $5 \mathrm{~m}$ (CÍRIO et al., 2003, LORENZI; MATOS, 2008).

Na descrição macroscópica das folhas de M. ilicifolia, são caracterizadas como folhas simples e formato oval, que passa para elíptico quando amadurecem (CARVALHO-OKANO, 1992) (Figura 2), embora apresentem variações. Normalmente são aculeadas nos bordos, medindo quando madura, de 10 a 15 cm. Radomski, Scheffer e Bull (2008) 
observaram os aspectos foliares da espécie (presença e ausência de espinhos no bordo foliar, proeminência das nervuras e do bordo foliar, textura e espessura das folhas, e tamanho do limbo), encontraram a existência de 9 morfotipos foliares.

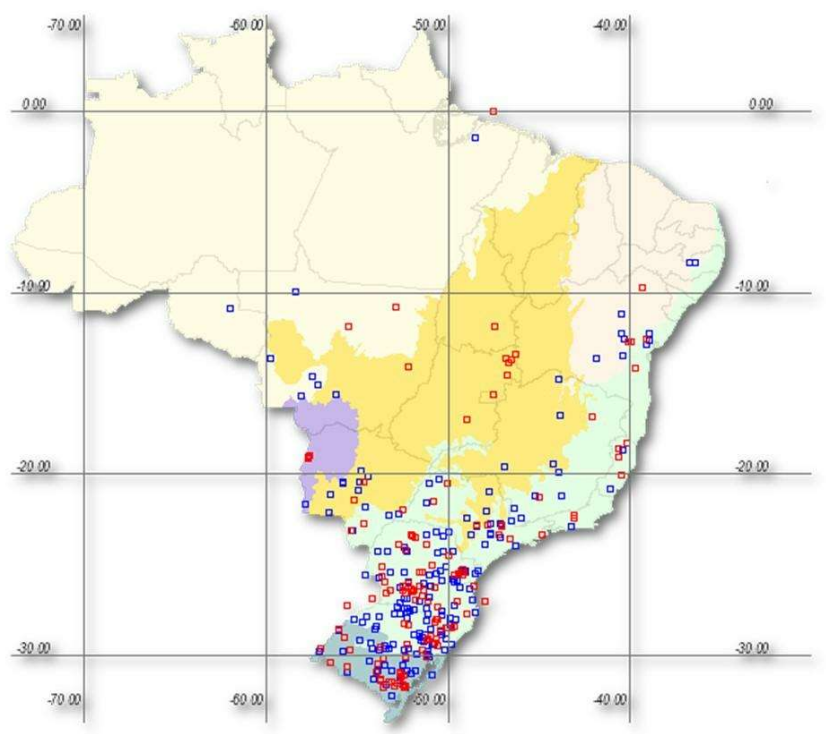

Figura 1. Pontos de coleta botânica de Maytenus ilicifolia Mart. ex. Reissek no Brasil (elaborado na plataforma Species Link - Centro de Referência em Informação Ambiental, CRIA).

Figure 1. Botanical collection points for Maytenus ilicifolia Mart. ex. Reissek in Brazil (elaborated on the Species Link platform Reference Center for Environmental Information, CRIA).

Suas flores apresentam-se pequenas, brancas esverdeadas ou amareladas, pouco vistosas (CARVALHO-OKANO, 1992) (Figura 2A). O florescimento ocorre de agosto a outubro, e os frutos (Figura 2D), de cor avermelhada e em formato de cápsula, amadurecem de janeiro a março. Suas sementes (Figura 2E) são dispersas no ambiente normalmente por aves (LORENZI; MATOS, 2008; PERLEBERG et al., 2021).

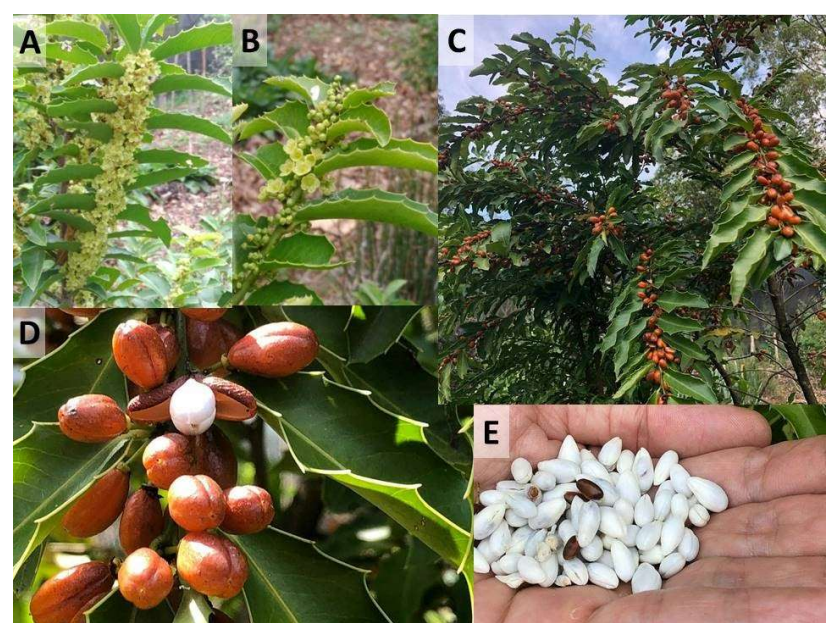

Figura 2. Aspectos morfológicos da Maytenus ilicifolia. A e B - flores C - aspecto geral da planta com frutos; D - frutos; E - sementes com e sem arilo (imagens dos autores).

Figure 2. Morphological aspects of Maytenus ilicifolia. A and B flowers; C - general aspect of the plant with fruits; D - fruits; E seeds with and without aryl (images of the authors).
O fruto de $M$. ilicifolia pode conter de 1 a 4 sementes (CARVALHO-OKANO, 1992). Os autores Rosa e Barros (1999) classificaram as sementes da espécie como oleaginosas, pois possuem 54\% de lipídios. As sementes de espinheira-santa são envoltas por arilo, que é uma excrescência carnosa que se forma no funículo ou no hilo, que é branco para essa espécie e fica exposta quando o fruto (cápsula) maduro se abre (CARVALHO-OKANO, 1992; MARIOT et al., 2005) (Figura 2D).

\subsection{Etnobotânica}

A espinheira-santa é amplamente utilizada na medicina popular em tratamentos de problemas estomacais, sendo bastante explorada por este motivo. Sua ação terapêutica deve-se a presença de metabólitos secundários, principalmente aqueles pertencentes aos grupos químicos triterpenos, flavonóides e taninos (MARIOT; BARBIERI, 2007a).

A infusão das folhas do Maytenus ilicifolia tem sido amplamente utilizada no Brasil pela medicina popular, por seus efeitos antiácidos, antiulcerogênicos, anti-inflamatória, cicatrizante, analgésica, antiasmática, antiácida, antitumoral e diurética, sendo suas principais citações, o uso no tratamento em desordens estomacais como gastrites e dispepsias (SOUZA-FORMIGONI et al., 1991; MONTANARI; BEVILACQUA, 2002; CIRIO et al., 2003; JORGE et al., 2004; MARIOT; BARBIERI, 2007a). O uso para tratamento de câncer de pele também é citado, como forma de emplastro e pelo decocto da planta (CORSINO et al., 1998).

A espécie tem sido utilizada nos Estados Unidos, através da medicina herbalista para repor a flora intestinal (MARIOT; BARBIERI, 2007a), como laxante e para regulagem da produção do ácido clorídrico do estômago (MELO et al., 2001). Em populações indígenas e rurais do Paraguai e Bolívia, a espécie é usada como contraceptivo, e mulheres no nordeste da Argentina também a utilizam para fins abortivos (MONTANARI et al., 1998).

Almeida et al. (2015) realizaram um estudo com feirantes em Pelotas (RS) e constataram que os entrevistados detêm conhecimentos diversos sobre a espinheira-santa, dentre eles a forma de uso, o período de tratamento e a indicação, sendo estas, no entanto, muito semelhantes entre si. Vale ressaltar que, os entrevistados, em geral, não apontaram informações sobre a procedência exata da espécie, essa recusa pode estar atrelada ao fato de que a matéria prima tenha sido obtida de modo ilegal, a partir do extrativismo em remanescentes florestais. No comércio, a planta pode ser encontrada na forma de extrato seco, tintura, cápsulas ou mesmo in natura (CIRIO et al., 2003).

\subsection{Fitoquímica}

Os principais metabólitos secundários associados à ação da $M$. ilicifolia são triterpenos, flavonoides, polifenóis e taninos (ITOKAWA et al., 1991; SHIROTA et al., 1994; MARIOT; BARBIERI, 2007a; PESSUTO et al., 2009).

Calou et al. (2014) relatam que friedelan-3-ol e o friedelan-3-ona são dois principais triterpenos identificados em extratos da espinheira-santa, podendo ser utilizados como marcadores moleculares para a espécie, e assim verificar se as plantas são verdadeiras ou adulterações. A maytenina e a 22hidroximaytenina são outros exemplos de triterpenos que pertencem à família Celastraceae, estes possuem ação anticâncer (CORSINO et al., 1998; HERNANDES et al., 2020). 
Di Stasi; Hiruma (2002) relatam a presença de alguns compostos bioativos, como a pristimerina, um triterpeno friedelano com ação antimalárica, e compostos fenólicos, com atividade inibitória na replicação do vírus HIV-1. Ohsaki et al. (2004) realizaram pesquisas químicas e descreveram quatro novos triterpenos: maytefolinas A, B e C e uvaol3cafeato. No estudo de Pereira et al. (2005) a M. aquifolia mostrou possuir teores mais altos de triterpenos em comparação a $M$. ilicifolia, embora o conteúdo de rendimentos de compostos fenólicos em $M$. ilicifolia fosse três vezes maior.

Vilegas et al. (1994) e Jorge et al. (2004) sugerem que as substâncias bioativas friedelan-3-ol e friedelan-3-one auxiliem no tratamento de doenças estomacais e úlceras, além de possuírem atividade antimicrobiana in vitro sobre Staphylococcus aureus, Klebsiella pneumoniae e Aspergillus flavus.

A análise da espécie, a partir dos extratos obtidos das cascas das raízes, indica a presença de triterpenos de quinonametida e compostos fenólicos como os principais metabólitos constituintes. A observação quantitativa dos extratos mostra que a quinonametida triterpena pristimerina é o principal componente de ambos os extratos (SANTOS et al., 2010).

Os flavonoides são uma classe de compostos que estão entre os mais abundantes nos vegetais, responsáveis em grande parte pelos sabores das plantas. Determinou-se que nas folhas o composto está na forma de heterosídeos (NEGRI, 2007; MARIOT; BARBIERI, 2007a). A presença de flavonoides e polifenóis no extrato da espinheira-santa exibem efeitos quimiopreventivos em várias linhas celulares de câncer humano (ARAÚJO-JUNIOR et al., 2013).

Os polifenóis são responsáveis por captar os radicais livres (ação antioxidante), despertando, assim, a possibilidade de serem utilizados em processos inflamatórios e cicatrizantes (VELLOSA et al., 2006). As folhas de M. ilicifolia foram testadas e o extrato aquoso é mais rico em compostos fenólicos do que o extrato alcoólico, sendo ambos mais ricos que o extrato etanólico de M. aquifolium (HAIDA et al., 2012). Esses compostos têm despertado grande interesse farmacêutico (NEGRI et al., 2009; PESSUTO et al., 2009). $\mathrm{Na}$ espinheira-santa, os tipos de polifenóis encontrados são as quercertinas e kaempferol (ROCHA et al., 2014). Alves et al. (2016) apontaram que a concentração de compostos fenólicos foi mais baixa em folhas secas do que em folhas frescas. Já os flavonóides tiveram números parecidos em ambos os extratos. Haida et al. (2012) observam em seus estudos que a atividade antioxidante não depende apenas do teor de compostos fenólicos existentes na espécie, mas também do sinergismo que pode ocorrer dos outros compostos ativos.

Taninos que derivam da catequina possuem atividade contra Helicobacter pilori, sendo o mais ativo a epigalocatequina-3-galato (MABE et al., 1999), a qual atua como gastroprotetor, o teor desse composto pode ser alterado conforme o nível de insolação e variação de características morfológicas. Os taninos possuem ações sequestrantes de radicais livres e atividade antioxidante, agem como uma camada que protege a mucosa e auxiliam no tratamento de doenças gástricas (CALOU et al., 2014; MARTINELLI et al., 2018). No extrato de folhas secas a presença de maiores concentrações de ácido gálico, catequina, ácido cefeico e quercetina foi observada, além da presença de epicatequina, já no extrato de folhas frescas foi registrado maiores quantidades de quercitina e kaempferol (ALVES et al. 2016).
Os taninos hidrolisáveis possuem a ação antiulcerogênica, que é considerada de grande relevância (SILVA et al., 2012), auxiliam como captadores de radicais livres, diminuindo a acidez gástrica (RAMOS et al., 2015). A Sociedade Brasileira de Farmacognosia aponta que a espinheira-santa está entre as principais espécies medicinais ricas em taninos, estes estão presentes na maioria dos extratos aquosos, sendo utilizados como marcadores no controle de qualidade de medicamentos fitoterápicos através de diferentes técnicas de avaliação e desenvolvimento tecnológico (SOARES et al., 2004).

Entre os polissacarídeos, foi descrita a presença de arabinogalactano (CIPRIANI et al., 2004), encontrado nas paredes celulares dos vegetais (OLIVEIRA JR et al., 2010), ao qual é sugerido estimular a atividade imunológica. Mendes, Machado e Falkenberg (2006) encontraram outros compostos em amostras in natura da espécie após análise, mono-galactosildiacilglicerol (MGDG), digalactosildiacilglicerol (DGDG), tri-galactosildiglicerol (TGDG), tetra-galactosildiacilglicerol (TeGDG), sulfoglicolipídios como o (TeGDG) sulfoquinovosildiacilglicerol (SQDG). Segundo Calou et al. (2014), os polissacarídeos são ingeridos normalmente no consumo de chás, com possíveis efeitos terapêuticos. Essas substâncias podem se ligar à mucosa gástrica, a protegendo pelo aumento da síntese de muco e sequestro de radicais livres (SATEL; MARQUES, 2015).

Sendo assim, a Maytenus ilicifolia configura-se como fitoterápico eficaz nos tratamentos de distúrbios no aparelho digestivo. É importante destacar que existem vários fatores que podem interferir nos teores de princípios ativos, os metabólitos secundários das plantas, como por exemplo, genética, clima, solo, local de plantio, a técnica de colheita, a secagem da planta e o processamento.

Chimin et al. (2008) relatam que a comprovação científica das ações terapêuticas de Maytenus ilicifolia foi iniciada com as pesquisas realizadas pelo médico e professor Aluízio Franca, da Faculdade de Medicina da Universidade Federal do Paraná, que no ano de 1920, relatou o sucesso obtido com esta espécie vegetal no tratamento de úlcera. Esse sucesso originou resultados, que mais tarde foram confirmados, apresentando efeitos similares à cimetidina e ranitidina na diminuição da acidez gástrica (JESUS; CUNHA, 2012).

Cirio et al. (2003) apontam que a espinheira-santa é muito importante para a farmacologia, pois possui atividades farmacológicas anti-inflamatórias, antiespasmódicas, antiácidas, cicatrizantes, podendo ser utilizada no tratamento de feridas e gastrites crônicas. Seus efeitos foram comprovados pelas pesquisas da Central de Medicamentos (CEME) do Ministério da Saúde do Brasil e entre os metabólitos que estão presentes são destacados os triterpenos, os taninos e os flavonóides, conforme já apontado acima (RAMOS et al., 2015).

Entre as comprovações científicas de seus efeitos terapêuticos se encontram os trabalhos de Souza-Formigoni et al. (1991) e Ferreira et al. (2004), os quais observaram que o extrato das folhas de espinheira-santa promove a secreção da mucosa gástrica de rãs, parecido com o efeito que o medicamento cimetidina apresenta.

Em análise de processos infecciosos do trato digestivo, os extratos secos foram efetivos contra Enterococcus faecalis e Staphylococcus aureus, porém, Salmonella enteritidis e Klebsiella pneumonia foram os microrganismos mais suscetíveis à ação dos extratos (ALVES et al.; 2016). Tabach; Oliveira (2003) e Alves et al. (2016) afirmam que a capacidade antioxidante e 
antimicrobiana da espécie está relacionada ao tipo de preparação, mesmo os extratos produzidos de folhas secas possuem efeito antiulcerogênico, maior concentração de compostos mioativos e atividade antibacteriana mais eficaz. No estudo de Kasse et al. (2008), a espinheira- santa foi escolhida para que a possível ação otoprotetora fosse avaliada

Ações antifúngicas também foram testadas, podendo ser utilizadas deste modo, também no controle de doenças em cultivos agrícolas. Cunico et al. (2002) realizaram estudos que comprovam a ação antifúngica do extrato etanólico de $M$. ilicifolia. Estes autores testaram três espécies de fungos causadores de doenças vegetais: o Colletotrichum acutatum, causador de antracnose, o Fusarium oxysporum, que causa morte de mudas e plantas jovens e o Cylindrocladium spathulatum, que é o agente causador da pinta-preta. Constatou-se que o extrato etanólico bruto das folhas de $M$. ilicifolia inibiu o crescimento micelial do fungo F. oxysporum, estimulou em $C$. acutatum e frações que inibiram o desenvolvimento de Cylindrocladium spathulatum (CUNICO et al., 2002). Pereira et al. (2005) observaram que as plantas cultivadas de $M$. ilicifolia são menos suscetíveis ao ataque microbiano do que $M$. aquifolium, sugerindo que níveis altos de fenóis poderiam auxiliar nesta proteção.

Quanto a uso e toxicidade, estudos afirmam que mesmo em doses mais altas, não presentaram toxicidade em ratos (OLIVEIRA et al., 1991), entretanto não é recomendada para gestantes, pois estudos em camundongos indicaram que pode interferir na receptividade uterina do embrião (CALOU et al., 2014). Outro estudo, realizado com camundongos e seres humanos, demonstrou que a planta possui toxicidade baixíssima e pouca possibilidade de efeitos tóxicos cumulativos (OLIVEIRA et al., 2009). Montanari; Bevilacqua (2002) verificaram que o extrato das folhas de $M$. ilicifolia causou perda na pré-implantação embrionária em ratos, mas sem efeito sobre implantação ou organogênese. Nos seres humanos, os efeitos colaterais podem ocorrer, dentre eles cita-se: cefaléia, boca seca, dor articular nas mãos e possível hipersensibilidade, ocasionando alergia aos componentes da planta, sendo contra indicada para crianças e gestantes (CALOU et al., 2014).

\subsection{Fitotecnia}

A reprodução da espinheira-santa pode se dar por diversas formas, possui reprodução assexuada, por rebentos nascidos das raízes, por estacas caulinares e até por meio da micropropagação, além da forma sexuada, por sementes. Ela possui boa germinação, mas as plantas que brotam das sementes possuem grande variabilidade genética e o teor de metabólitos secundários pode variar bastante (LIMA et al., 2009), o que pode ser não desejável em sistemas de produção da espécie.

A capacidade de germinação dessas sementes foi testada após diferentes condições de armazenamento, sendo a câmara fria o método que obteve melhores resultados. Essa forma de armazenamento foi capaz de preservar a semente, fazendo com que sua umidade natural fosse diminuída lentamente e a integridade da mesma fosse protegida (ROSA; BARROS, 1999).

A partir dos dados apresentados pelo trabalho de Mariot et al. (2005) verificou-se que não é necessário retirar o arilo para que a espinheira-santa germine. Segundo Magalhães (2002), a semeadura pode ocorrer no início da primavera, a formação de mudas da espécie é lenta, e dura de 4 a 5 meses, o transplante das mesmas deve ocorrer no verão, preferencialmente ainda na época das chuvas. A espinheirasanta requer regas frequentes no início, e até os dois primeiros anos de idade, porém, a quantidade pode ser reduzida progressivamente, sendo mais necessária em épocas mais secas.

O método de estaquia é eficiente quando realizado em matrizes selecionadas, dando origem a um material mais homogêneo geneticamente (LIMA et al., 2009). Porém, quando as estacas são provenientes de plantas adultas fornecem material vegetativo com menor facilidade de enraizamento, sendo a utilização de estacas de plantas jovens preferível, no entanto, processos e técnicas que rejuvenescem as plantas matrizes podem auxiliar no enraizamento.

Para o enraizamento, Masson (2017) realizou um estudo onde foram utilizadas diferentes doses do regulador de crescimento AIB (ácido indol-butírico) em alporques de Maytenus ilicifolia. No experimento, o autor percebeu que não houve crescimento das raízes, mesmo com a aplicação do AIB, demonstrando dificuldade para que a espécie possa ter para enraizar por alporques. Kowalski et al. (2008) observaram que a adição de composto orgânico na terra é capaz de proporcionar maior comprimento da parte aérea da planta durante a estaquia, mostrando que essa mistura é mais vantajosa do que utilizar apenas terra.

Quanto ao plantio da espinheira-santa, ele pode ser adensado na linha, já que a planta aceita podas, sendo estas, inclusive, o modo de obtenção da matéria vegetal, isto é, as folhas. Assim, a densidade de 4.000 plantas por hectare, no espaçamento de $1,0 \mathrm{~m}$ na linha e 2,5 m entre linhas é considerada apropriada (MAGALHÃES, 2002). Consideramos que outras formas de cultivo, como os policultivos ou sistemas agroflorestais, são bastante apropriados para a produção da espécie (PASTUR et al., 2012; BIASI et al., 2017; BORGES et al. 2019; STEENBOCK et al., 2020), podendo ser, inclusive, utilizada na restauração ecológica de áreas de preservação permanentes (APPs) ou reservas legais (RLs) (DALPIZOL et al., 2021), no entanto, são ainda incipientes as experiências com o cultivo da espinheira-santa nestas formas de cultivo. Borges et al. (2019) registram uma diminuição de compostos de interesse com o aumento do sombreamento, o que deve ser considerado em sistemas de policultivo.

Sobre as condições de luminosidade, Rocha et al. (2014) realizaram um estudo onde as plantas que estavam a pleno sol, e sofreram o manejo de poda rasa, não apresentaram bom desenvolvimento após esta poda, enquanto as plantas que estavam sob área sombreada, sofrendo o mesmo tipo de poda, voltaram ao crescimento mais rapidamente. De toda forma, a poda drástica favoreceu o número de brotações. Estas características reforçam a ideia e o potencial de uso da espécie em sistemas agroflorestais. A $M$. ilicifolia necessita de condições equilibradas e não estressantes para rebrotar, ou seja, ambientes com temperaturas amenas e menor insolação direta, como já demonstrado por Rocha et al. (2014).

Steenbock et al. (2003) também realizaram uma comparação de duas produções de espinheira-santa, uma estando a pleno sol e a outra em ambientes semi-sombreados. Verificaram que os indivíduos que estavam a pleno sol apresentaram caules principais com menor diâmetro, e praticamente todas as folhas estavam inseridas nos ramos primários. Já em sub-bosque, as folhas apresentaram-se inseridas no caule principal, com altura menor e folhas maiores. Considera-se então a partir desse estudo, que o "número de ramos primários com folhas" é um parâmetro 
adequado para indicar o rendimento foliar da espinheirasanta. Desta forma, pode-se entender que a realização de podas de formação em plantas em ambiente sombreado pode apresentar benefícios na produção da espécie.

Radomski et al. (2008) apontam que há uma grande diversidade de fenótipos e genótipos. Deve-se considerar o fato da espécie ser alógama (polinização cruzada) no estabelecimento de programas de melhoramento genético da espécie. Além disso, características como adubação, poda e sombreamento interferem na produtividade (folhas) e consequentemente nas quantidades de seus compostos químicos, os quais possuem relação direta com as propriedades terapêuticas da $M$. ilicifolia. Entendemos também ser necessário que haja mais estudos sobre a morfofisiologia relacionada à fitoquímica da espécie no processo de produção. Os mesmos autores observam que há uma tendência dos teores de lignina com relação aos morfotipos das folhas, ou seja, folhas com menos espinhos e mais delgadas possuem menor teor de lignina. O tamanho das folhas da espinheira-santa apresenta relação com o aumento da biomassa e maior concentração de metabólitos secundários (triterpenos) que possuem a ação farmacológica e podem servir como um bom tipo de característica a ser considerada num programa de melhoramento genético (BUFFA FILHO et al., 2002; MARIOT et al., 2005).

Radomski et al. (2004) observaram diferenças na morfologia e nas concentrações de taninos e teores de fenóis em folhas de $M$. ilicifolia. As folhas que estavam a pleno sol eram menores, mais amareladas, com estrutura mais sólida, tinham mais espinhos nas bordas e maior concentração de taninos, mostrando que a luminosidade influencia na produção de polifenóis totais, polifenóis não tanantes e taninos.

As condições para desenvolver os princípios ativos da planta nem sempre serão as mesmas para a produção de biomassa, uma vez que as substâncias ativas se alteram quando a erva é submetida a estresses ambientais (CIRIO et al., 2003). Radomski et al. (2004) e Mossi et al. (2009) apontam que os compostos fitoquímicos existentes na espinheira-santa são alterados em função do ambiente em que está inserida. Ou seja, fatores microambientais (condições do solo, luz solar e microclima) e fatores genéticos, podem exercer influência na produção de triterpenos, taninos e polifenóis.

Na produção de fitomassa e matéria-prima, a desfolha da planta não deve ser realizada, pois a poda de galhos já estimula o crescimento vegetativo, e deste modo, primeiro realiza-se a poda, para depois retirar as folhas (ROCHA et al., 2014). A altura recomendada para a primeira poda é de $50 \mathrm{~cm}$ e nos anos posteriores logo acima das ramificações da poda anterior (MAGALHÃES, 2002). Rocha et al. (2014) recomendam, de outro modo, que para que haja rebrota de vários ramos, no primeiro ano da planta deve-se realizar a poda a $20 \mathrm{~cm}$ do solo.

Existe a necessidade de uniformizar os teores dos princípios ativos para a utilização pela indústria farmacêutica. Para a reprodução com ênfase em uso farmacêutico é necessário selecionar as plantas com os componentes químicos específicos para a produção de fitoterápicos (PEREIRA et al., 2005). O estudo de Mossi et al. (2009) propõe medidas apropriadas para o cultivo, visando o aumento nas concentrações de taninos e compostos específicos como os triterpenos, friedelan-3-ona, friedelan-3ol e friedelina.
Para que se realize um bom programa de melhoramento genético é necessário que se possa estimar as correlações fenotípicas e genotípicas, já que esta pré-seleção é essencial, devido ao alto custo das análises para determinar e quantificar os metabólitos secundários com potencial farmacológico, como as que envolvem cromatografia (MARIOT; BARBIERI, 2007a). Na cultura de espinheira-santa, podem ocorrer cochonilhas, ácaros, pulgões e formigas, que podem causar prejuízos à planta, pois acabam por reduzir a área foliar (CIRIO et al., 2003).

Algumas das características são muito importantes para programas de seleção e melhoramento desta espécie, como a maior produção de massa foliar em relação à produção de ramos, e a ocorrência de folhas com ausência ou poucos espinhos no bordo, característica que facilitaria a execução da poda e a manipulação do material para produção de fitoterápicos. Porém, Pereira et al. (2005) dizem que os acessos de $M$. ilicifolia que apresentam um número reduzido ou quase nenhum espinho nas folhas, às vezes, são comercialmente rejeitadas, porque os consumidores suspeitam sobre a autenticidade e o valor terapêutico das mesmas. Esse aspecto morfológico não está comprovado para ser correlacionado aos rendimentos de qualquer classe de metabólito secundário.

Para secagem e armazenamento das folhas, o trabalho de Negri (2007), verificou que a temperatura de 40 graus é a melhor para secagem, a fim de preservar as características químicas da espécie quanto a sua qualidade medicinal, retirando a umidade de maneira lenta. Porém, em todas as temperaturas testadas não foram capazes de protegê-las de contaminação de bolores, leveduras e outros microrganismos. É necessário que haja uma padronização de secagem para as plantas, pois elas podem perder seu efeito como fitoterápico. Alguns agricultores, ou beneficiadores da planta, acabam realizando a secagem de maneira inadequada, sem o controle da temperatura, sendo esta essencial pela qualidade e teores de óleos essenciais. No geral, temperaturas por volta de $40{ }^{\circ} \mathrm{C}$ são as mais indicadas para que não ocorram alterações na atividade antioxidante (MELO et al., 2001; BLANK et al., 2007).

\subsection{Adulterações}

Segundo Cirio et al. (2003) e Mariot; Barbieri (2007b), a espécie $M$. ilicifolia tem sido ainda obtida a partir do extrativismo, das quais são coletados os ramos e as folhas. A comercialização de plantas medicinais se dá, em grande parte, pelo comércio informal, podendo se considerar, como uma forma de se transmitir o conhecimento tradicional das comunidades (MINNAERT; FREITAS, 2010; ROCHA et al., 2013). Por outro lado, estes locais podem apresentar má higiene, deficiência de conhecimento técnico do comerciante para o comprador (não informando sobre a segurança do uso das plantas medicinais ou uso incorreto) e como consequencia, a baixa qualidade do material vendido ou mesmo falsificações ou adulterações. Teixeira et al. (2018) apontam vários problemas com a qualidade das ervas comercializadas, registrando, inclusive, que apenas 37\% das amostras apresentam teor de epicatequina recomendado. No mercado farmacêutico, a espécie pode ser encontrada em forma de cápsulas, tintura, extrato liofilizado e in natura para utilizar como chá (CIRIO et al., 2003).

Além de sofrer com o extrativismo, a Maytenus ilicifolia é confundida com outras espécies, possibilitando adulterações no material comercializado (NASCIMENTO et al. 2005; 
AMARAL et al., 2021; SANTOS et al., 2021), a chamada Sorocea bonplandii, que possui como nome popular mata-olho, é uma planta comumente confundida com a espinheira-santa. Pertence à família Moraceae, possui semelhanças quanto a forma da folha, mas quando se averígua a parte celular de ambas é possível verificar diferenças quanto a anatomia. Essa planta possui de 6 a 12 metros de altura, é distribuída por todo território brasileiro e também é de interesse farmacêutico, pois apresenta um valor medicinal similar ao da espinheira-santa, a partir de pesquisas analisou-se a presença de ações analgésicas e antiulcerogênicas (CALIXTO et al. 1993).

Outra espécie que acaba gerando confusão é a Zollernia ilicifolia, da família Fabaceae. Essa planta também possui princípios ativos curativos, porém, são raros os estudos farmacológicos e fitotoxicos (DI STASI; HIRUMA-LIMA, 2002). O maior problema em relação a verificação dos indivíduos é que eles são vendidos em forma de chá, secos, macerados e em sacos plásticos. É impossível perceber a diferença sem que haja um estudo específico, em laboratório. Daí a necessidade de maior fiscalização e controle das plantas vendidas em mercados.

Alberton et al. (2002) e Ali et al. (2021) argumentam que existem trabalhos sendo desenvolvidos para que haja controle de qualidade da espinheira-santa de amostras comerciais. A utilização da cromatografia detecta a presença dos princípios ativos de interesse ou de adulterantes. Foram identificados três marcadores cromatográficos para Sorocea bonplandii e um para Zollernia ilicifolia. A identificação de $M$. ilicifolia pode ser confirmada a partir da presença de friedelina e friedelanos.

\section{DISCUSSÃO}

Consideramos que o cultivo da espinheira-santa pode ser uma forma de garantir sua conservação e preservação, configurando a sua conservação on farm (MAHARJAN et al., 2011; JOSE, 2012; SANTONIERI; BUSTAMONT, 2016; KINHOÉFBÈ et al., 2020). O cultivo da espinheira-santa poderia ser uma alternativa para aumentar a renda de pequenas propriedades agrícolas (AMOROZO, 2008; MATADUIA et al., 2014), sem deixar de ser interessante também para agriculturas de maior escala, e atender a demanda da indústria farmacêutica, reduzindo a erosão genética e risco de extinção causada pelo extrativismo e superexploração (FERNANDES et al., 2013). Lima et al. (2017) reforçam que o uso da sociobiodiversidade incentiva e promove a criação de emprego e renda, além de contribuir para a conservação das florestas e recursos naturais, embora existam ainda empecilhos para este avanço. Outro fator a ser considerado, é que sua inserção em modelos produtivos pode garantir a qualidade da matéria-prima, evitando falsificações e obtendo material mais homogêneo quanto à qualidade e quantidade dos princípios ativos. Consideramos ainda que a espécie é bastante apropriada para uso em restauração ecológica, sobretudo em áreas de preservação permanente (APPs) e reservas legais (RL), pois aceita poda, sendo suas folhas a parte extraída para exploração, consistindo a matéria prima para uso medicinal, promovendo, desta forma, a geração de renda nestas áreas, sendo capaz de reduzir os custos do processo de restauração.

O seu cultivo pode ser aproveitado para uso pelas próprias comunidades, pois o uso consciente de espécies medicinais tem sido de grande valia nos tratamentos terapêuticos, sobretudo aquelas comunidades que se encontram distantes dos grandes centros ou quando o recurso financeiro é um impeditivo ao acesso aos medicamentos formais dos sistemas de saúde (ALVES et al., 2015; LEANDRO et al., 2017; BORGES et al., 2020)

Desta forma, entendemos a necessidade de mais estudos, pesquisas científicas e áreas de produção de referência para o desenvolvimento de políticas públicas afim de incentivar a produção da espécie e da sociobiodiversidade de modo geral, sobretudo em agroecossistemas como policultivos ou sistemas agroflorestais, que são capazes de aliar a produção agrícola, a conservação ambiental e a prestação de serviços ecossistêmicos, utilizando um plantio mais diversificado de espécies vegetais, ou seja, muito mais parecido com o que ocorre na própria natureza. Deste modo, e nestes sistemas, a heterogeneidade das comunidades vegetais plantadas podem gerar diversos produtos, aumentando os lucros, a produtividade e a estabilidade econômica e ambiental da propriedade agrícola (NICHOLLS; ALTIERI, 2019). Pesquisas sobre produtividade da espécie também são bastante escassas na literatura científica, o que pode se tornar um gargalo ao incentivo aos agricultores.

\section{CONSIDERAÇÕES FINAIS}

Neste trabalho procuramos reunir informações sobre a cadeia produtiva e conhecimentos acerca da espinheira-santa verdadeira. Foram reunidas e utilizadas 67 publicações científicas (que abordaram o uso e conhecimento da espinheira-santa), divididas entre os temas, botânica, ecologia, etnobotânica, fitoquímica, fitotecnia e adulterações.

Os conhecimentos em botânica e ecologia são bem descritos na literatura científica, bem como é bem descrito seu uso popular. A grande maioria dos trabalhos publicados sobre a espécie aborda o conhecimento químico de sua composição e comprovações científicas de seus efeitos terapêuticos. Existem ainda informações sobre sua reprodução, obtenção de sementes e produção de mudas.

Experiências sobre modelos de produção, sobretudo modelos de policultivos ou de sistemas agroflorestais já existem, porém ainda são escassos na literatura científica, apontando um vácuo no conhecimento e das experiências nesta abordagem.

Outras informações apontam que a espécie é explorada por extrativismo, seu mercado em grande parte é informal, o que deriva em muitos problemas quanto a adulterações, falsificações e conservação da espécie. Seu estabelecimento em sistemas de produção pode ser um passo decisivo na conservação e preservação da espécie e na produção de matéria-prima para fitoterápicos de alta qualidade.

\section{AGRADECIMENTOS}

Ao CNPQ pela bolsa de Iniciação Científica (PIBIC Instituto de Botânica - SIMA/SP) de Jéssica Soares Garcia.

\section{REFERENCIAS}

ALBERTON, M. D.; FALKENBERG, D. B.; FALKENBERG, M. B. Análise cromatográfica de fitoterápicos a base de espinheira-santa (Maytenus ilicifolia). Revista Brasileira de Farmacognosia, Curitiba, v. 12, S. 1, p. 11-13, 2002. DOI: https://doi.org/10.1590/S0102-695X2002000300006.

ALBUQUERQUE, U. P.; MEDEIROS, P. M.; SOUZA, T. A.; SILVA, T. C.; CUNHA, L. V. F. C.; OLIVEIRA, G. J.; ALMEIDA, C. F. C. B. R. The role of ethnobotany 
and environmental perception in the conservation of Atlantic Forest fragments in northeastern Brazil. Bioremediation, Biodiversuty and Bioavaillability, v. 2, n. 1, p. 27-34, 2008.

ALI, S.; RECH, K. S.; BADSHAH, G.; SOARES, F. L. F.; BARISON, A. ${ }^{1} \mathrm{H}$ HR-MAS NMR-Based metabolomic fingerprinting to distinguish morphological similarities and metabolic profiles of Maytenus ilicifolia, a Brazilian medicinal plant. Journal of Natural Products, v. 84, p. 1707-1714, 2021.

DOI: https://doi.org/10.1021/acs.jnatprod.0c01094.

ALMEIDA, C.; BARBIERI, R. L.; RIBEIRO, M. V.; LOPES, C. V.; HECK, R. M. Espinheira-santa (Maytenus ilicifolia Mart. ex Reiss.): saber de erveiros e feirantes em Pelotas (RS). Revista Brasileira de Plantas Medicinais, Botucatu, v. 17, n. 4, p. 722-729, 2015. DOI: https://doi.org/10.1590/1983-084X/14_003.

ALVES, A. O.; OLIVEIRA, R. M.; WEISS, G. C. C.; BONADIMAN, B. S. R.; SANTOS, R. C. V.; CRUZ, I. B. M. Análise fitoquímica e avaliação das atividades antioxidante e antimicrobiana de Maytenus ilicifolia. In: Congresso Brasileiro de Ciência e Tecnologia de Alimentos, XXV, 2016. Anais... Disponível em: http://www.ufrgs.br/sbctars-

eventos/xxvcbcta/anais/files/1509.pdf.

ALVES, J. J. P.; LIMA, C. C.; SANTOS, D. B.; BEZERRA, P. D. F. Conhecimento popular sobre plantas medicinais e o cuidado da saúde primária: um estudo de caso da comunidade rural de Mendes, São José de Mipibu/RN. Carpe Diem: Revista Cultural e Científica, Natal, v. 13, n. 1, p. 136-156, 2015.

AMARAL, F. M.; MONTEIRO, S. S. R.; FERNANDES, T.; TEIXEIRA, D. F.; LUCCHETTI, L.; JACOB, S. C.; PAIVA, S. R.; JOFFILY, A. Pharmacobotanical characterization of Monteverdia ilicifolia (Mart. ex Reiss.) Biral leaves and its adulterants sold as medicinal tea in Brazil: a contribution to quality control Boletín Latinoamericano y Del Caribe de Plantas Medicinales y Aromáticas, v. 20, n. 4, p. 386-393, 2021. DOI: https://doi.org/10.37360/blacpma.21.20.4.28.

AMOROZO, M. C. M. Maintenance and management of agrobiodiversity in small-scale agriculture. Functional Ecosystems and Communities, v. 2, p. 11-20, 2008.

ANDERSON, C. R.; PIMBERT, M. P.; CHAPPEL, M. J.; BREM-WILSON， J.; CLAEYS， P.; KISS， C.; MAUGHAN, C.; MILGROON, J.; MCALLISTER, G.; MOELLER, N.; SINGH, J. Agroecology now connecting the dots to enable agroecology transformations. Agroecology and Sustainable Food Systems, v. 44, n. 5, p. 561-565, 2020. DOI: https://doi.org/10.1080/21683565.2019.1709320.

ARAÚJO-JÚNIOR, R. F.; OLIVEIRA, A. L. C. S. L.; PESSOA, J. B.; GARCIA, B. V.; GUERRA, G. C. B.; SOARES, L. A. L.; SOUZA, T. P.; PETROVICK, P. R.; ARAÚJO, A. A. Maytenus ilicifolia dry extract protects normal cells, induces apoptosis and regulates Bcl-2 in human cancer cells. Experimental Biology and Medicine, Maywood, v. 238, n. 11, p. 1251-1258, 2013. DOI: $10.1177 / 1535370213494563$.

AZEVEDO, C. M. A. A regulamentação do acesso aos recursos genéticos e aos conhecimentos tradicionais associados no Brasil. Biota Neotropica, Campinas, v. 5, n. 1, p. 1-9, 2005. DOI: https://doi.org/10.1590/S167606032005000100002 .
BARREIRO, E. J.; BOLZANI, V. S. Biodiversidade: fonte potencial para descoberta de fármacos. Química Nova, Rio de Janeiro, v. 32, n. 3, p. 679-688, 2009. DOI: http://dx.doi.org/10.1590/S0100-40422009000300012.

BIASI, R.; BRUNORI, E.; FERRARA, C.; SALVATI, L. Towards sustainable rural landscapes? a multivariate analysis of the structure of traditional tree cropping systems along a human pressure gradient in a Mediterranean region. Agroforest System, v. 91, p. 1199-1217, 2017.

DOI: https://doi.org/10.1007/s10457-016-0006-0.

BLANK, A. F.; COSTA, A. G.; BLANK, M. F. A.; CAVALCANTI, S. C. H.; ALVES, P. B.; EHLERT P. A. D.; INNECCO, R.; SOUSA, I. F. Influence of season, harvest time and drying on Java citronella (Cymbopogon winterianus Jowitt) volatile oil. Revista Brasileira de Farmacognosia, Curitiba, v. 17, n. 4, p. 557-564, 2007. DOI: $\quad$ http://dx.doi.org/10.1590/S0102695X2007000400014.

BORGES, J. S.; BAMPI, A. C.; CARNIELLO, M. A. Práticas e saberes: as várias faces que permeiam o uso de plantas na medicina popular. Gaia Scientia, João Pessoa, v. 14, n. $3, \quad$ p. 51-74, 2020. DOI: https://doi.org/10.22478/ufpb.1981-

1268.2020v14n3.50874.

BORGES, R.; BOFF, M. I. C.; MANTOVANI, A.; RADOMSKI, M. I. Effect of cover on the development and production of secondary compounds of Maytenus ilicifolia and Ilex paraguariensis in agroforestry systems. Ciência Florestal, Santa Maria, v. 29, n. 4, p. 1630-1643, 2019. DOI: https://doi.org/10.5902/1980509832280.

BROOKS, T. M.; MITTERMEIER, R. A.; FONSECA, G. A. B.; GERLACH, J.; HOFFMANN, M.; LAMOREAUX, J. F.; MITTERMEIER, C. G.; PILGRIM, J. D.; RODRIGUES, A. S. L. Global biodiversity conservation priorities. Science, v. 313, p. 58-61, 2006. DOI: 10.1126/science.1127609.

BUFFA FILHO, W.; CORSINO, J.; BOLZANI, V. S.; FURLAN, M.; PEREIRA, A. M. S.; FRANÇA, S. C. Quantitative determination of cytotoxic friedo-noroleanane derivatives from five morphological types of Maytenus ilicifolia (Celastraceae) by reverse-phase high performance liquid chromatography. Phytochemical Analysis, Sussex, v. 13, n. 2, p. 75-78, 2002. DOI: https://doi.org/10.1002/pca.626.

CALIXTO, J. B.; MESSANA, I.; DELLA MONACHE, F.; FERRARI, F.; BISOGNIN, T.; YUNES, R. A. Pharmacological analysis of the methanolic extract and sorocein A, a new Diels-Alder compound isolated from the roots of Sorocea bonplandii Bailon in the isolated rat uterus and guinea pig ileum. General Pharmacology, Oxford, v. 24, n. 4, p. 983-989, 1993. DOI: 10.1016/0306-3623(93)90177-y.

CALOU, I. B. F.; LIMA, L. A. R.; FERREIRA, J. A. N.; CERQUEIRA, G. S. A atividade gastroprotetora da Maytenus ilicifolia e Maytenus aquifolium. Revista Saúde e Ciência, Campina Grande, v. 3, n. 2, p. 33-42, 2014. DOI: https://doi.org/10.35572/rsc.v3i2.294

CARVALHO-OKANO, R. M. D. Estudos taxonômicos do gênero Maytenus Mol. emend. Mol. (Celastraceae) no Brasil extra-amazônico, SP, Brasil. 261f. Tese (Doutorado) - Universidade Estadual de Campinas, Campinas, SP. 1992. Disponível em: 
http://www.repositorio.unicamp.br/handle/REPOSIP /315119.

CDB. Convention on Biological Diversity. Brazil - Main Details. Disponível em: https://www.cbd.int/countries/profile/?country=br. Acessado em 30/08/2021.

CHIMIN, A.; LIMA, E. L.; BELTRAME, F. L.; PEREIRA, A. V.; ESMERINO, L. A. Avaliação da qualidade de amostras comerciais de Maytenus ilicifolia (espinheirasanta) comercializadas no estado do Paraná. Latin American Journal of Pharmacy, Buenos Aires, v. 27, n. 4, p. 591-597, 2008.

CIPRIANI, T. R.; MELLINGER, C. G.; GORIN, P. A. J.; IACOMINI, M. An arabinogalactan isolated from the medicinal plant Maytenus ilicifolia. Journal of Natural Products, v. 67, n. 4, p. 703-706, 2004. DOI: 10.1021/np034043f.

CIRIO, G. M.; DONI FILHO, L.; MIGUEL, M. D.; MIGUEL, O. G.; ZANIN, S. M. W. Inter-relação de parâmetros agronômicos e físicos de controle de qualidade de Maytenus ilicifolia, Mart. Ex. Reiss (espinheirasanta) como insumo para a indústria farmacêutica. Visão Acadêmica, Curitiba, v. 4, n. 2, p. 67-76, 2003. DOI: http:dx.doi.org/10.5380/acd.v4i2.525

CORSINO, J.; ALÉCIO, A. C.; RIBEIRO, M. L.; FURLAN, M.; PEREIRA, A. M. S.; DUARTE, I. B.; FRANÇA, S. C. Quantitative determination of maitenin and 22 hydroxymaitenin in callus of Maytenus aquifolium (Celastraceae) by reverse phase high performance liquid chromatography. Phytochemical Analysis, v. 9, n. 5, p. 245-247, 1998.

CUNICO, M. M.; CÍRIO, G. M.; MIGUEL, O. G.; MIGUE, M. D.; MONTRUCCHIO, D. P.; AUER, C. G.; GRIGOLETTI JR., A. Contribuição ao estudo da atividade antifúngica da Maytenus ilicifolia Mart. ex Ress., Celastraceae. Revista Brasileira de Farmacognosia, Curitiba, v. 12, n. 1, p. 69-73, 2002.

DALPIZZOL, J.; VICENTE, D. L. S.; DEMETRIO, L.; GOULART, M. M.; AQUINO, M. G. C.; FOCKINK, G.; KANIESKI, M. R. Avaliação de técnicas nucleadoras em uma Área de Preservação Permanente no Planalto Serrano. Biodiversidade, Cuiabá, v. 20, n. 2, p. 161-180, 2021.

DI STASI, L. C.; HIRUMA-LIMA, C. A. Plantas Medicinais na Amazônia e na Mata Atlântica. 2 ed. São Paulo: Editora Unesp. 2002. 608p.

DiAS, J. E.; LAUREANO, L. C.; MING, L. C. Cadeia produtiva do óleo de amendoas de gueroba (Syagrus oleracea): geração de renda para agricultores familiares e promoção da agrobiodiversidade. Revista Brasileira de Agroecologia, Dois Vizinhos, v. 9, n. 1, p. 122-133, 2014.

FERNANDES, G. P.; KERNTOPF, M. R.; LEMOS, I. C. S. Superexploração de recursos naturais: implicações para sociobiodiversidade, a bioprospecção e a etnomedicina. Ensaios e Ciência: Ciências Biológicas, Agrárias e da Saúde, v. 17, n. 2, p. 95-105, 2013. DOI: https://doi.org/10.17921/14156938.2013v17n2p\%25p.

FERREIRA, P. M.; OLIVEIRA, C. N.; OLIVEIRA, A. B.; LOPES, M. J.; ALZAMORA, F.; VIEIRA, M. A. R. A lyophilized aqueous extract of Maytenus ilicifolia leaves inhibits histamine-mediated acid secretion in isolated frog gastric mucosa. Planta, v. 219, n. 2, p. 319-324, 2004. DOI: $10.1007 /$ s00425-004-1222-9.

FLORA DO BRASIL 2020. Disponível em http://floradobrasil.jbrj.gov.br/. Acessado em 30/08/2021.

GASPER, A. L.; STEHMANN, J. R.; ROQUE, N.; BIGIO, N. C.; SARTORI, A. L. B.; GRITTZ, G. S. Brazilian herbaria: an overview. Acta Botanica Brasilica, Brasília, v. 34 , n. 2 , p. 352-359, 2020. DOI: https://doi.org/10.1590/0102-33062019abb0390.

GBEDOMON, R. C.; SALAKO, V. K.; FANDOHAN, A. B.; IDOHOU, A. F. R.; KAKAI, R. G.; ASSOGBADJO, A. E. Functional diversity of home gardnes and their agrobiodiversity conservation benefits in Benin, West Africa. Journal of Ethnobiology and Ethnomedicine, v. 13, n. 66, 2017. DOI: https://doi.org/10.1186/s13002-017-0192-5.

HAIDA, K. S.; HAAS, J.; LIMA, D. S.; SILVA, S. J.; LIMANA, S.; RODRIGUES, R. T. Atividade antioxidante e compostos fenólicos de Maytenus ilicifolia e Maytenus aquifolium. Revista Saúde e Pesquisa, Maringá, v. 5, p. 360-368, 2012.

HALL, J. S.; ASHTON, M. S.; GAREN, E. J.; JOSE, S. The ecology and ecosystem services of native trees: implications for reforestation and land restoration in Mesoamerica. Forest Ecology and Management, Amsterdam, v. 261, p. 1553-1557, 2011. DOI: https://doi.org/10.1016/j.foreco.2010.12.011.

HARTWIG, B. R.; RODRIGUES, D. S.; OLIVEIRA JR, C. J. F. Erva-baleeira, uma possibilidade real da sociobiodiversidade para modelos sustentáveis de produção. Holos, Natal, v. 3, e9409, 2020. DOI: https://doi.org/10.15628/holos.2020.9409.

HERNANDES, C.; MIGUITA, L.; SALES, R. O.; SILVA, E. P.; MENDONÇA, P. O. R.; SILVA, B. L.; KLINGBEIL, M. F. G.; MATHOR, M. B.; RANGEL, E. B.; MARTI, L. C.; COPPEDE, J. S.; NUNES, F. D.; PEREIRA, A. M. S.; SEVERINO, P. Anticancer activities of the quinone-methide triterpenes maytenin and 22- $\beta$-hydroxymaytenin obtained from cultivated Maytenus ilicifolia roots associated with down-regulation of miRNA-27a and miR-20a/miR-17-5p. Molecules, v. 25: 760, 2020. DOI: $10.3390 /$ molecules 25030760.

ITOKAWA, H.; SHIROTA O.; IKUTA, H.; MORITA, H.; TAKEYA, K.; LITAKA, Y. Triterpenes from Maytenus ilicifolia. Phytochemistry, Oxford, v. 30, n. 11, p. 37133716, 1991. DOI: https://doi.org/10.1016/00319422(91)80096-J.

JESUS, W. M. M.; CUNHA, T. N. Estudo das propriedades farmacológicas da espinheira-santa (Maytenus ilicifolia Mart. ex Reissek) e de duas espécies adulterantes. Revista Saúde e Desenvolvimento, v. 2, n. 1, p. 21-27, 2012.

JORGE, R. M.; LEITE, J. P. V.; OLIVEIRA, A. B.; TAGLIATI, C. A. Evaluation of antinociceptive, antiinflammatory and antiulcerogenic activities of Maytenus ilicifolia. Journal of Ethnopharmacology, Lausanne, v. 94, n. 1, p. 93-100, 2004. DOI: 10.1016/j.jep.2004.04.019.

JOSE, S. Agroforestry for conserving and enhancing biodiversity. Agroforestry Systems, v. 85, p. 1-8, 2012. DOI: https://doi.org/10.1007/s10457-012-9517-5.

KASSE, C. A.; CRUZ, O. L. M.; IBA, L. C. M.; COSTA, H. O.; LOPES, E. C.; COELHO, F. O uso de Maytenus ilicifolia na prevenção da ototoxicidade induzida pela cisplatina. Revista Brasileira de Otorrinolaringologia, 
v. 74 , n. 5 , p. 712-717, 2008. Doi: https://doi.org/10.1590/S0034-72992008000500012.

KINHOÉGBÈ, G.; DJÈDATIN, G.; LOKO, L.E.Y.; FAVI, A.G.; ADOMOU, A.; AGBANGLA, C.; DANSI, A. Onfarm management and participatory evaluation of pigeonpea (Cajanus cajan [L.] Millspaugh) diversity across the agroecological zones of the Republic of Benin. Journal of Ethnobiology and Ethnomedicine, v. 16, n. 24, p. 1-21, 2020. DOI: https://doi.org/10.1186/s13002-020-00378-0.

KOWALSKI, A. P. D. J.; SIGNOR, D.; MACHADO, E. M.; BIASI, L. A.; LIMA, D. M. Influência da qualidade da semente e do tipo de substrato na formação de mudas de espinheira-santa. Scientia Agraria, Curitiba, v. 9, n. 1, p. 15-20,

2008.

DOI: http://dx.doi.org/10.5380/rsa.v9i1.10127.

LEANDRO, Y. A. S.; JARDIM, I. N.; GAVILANES, M. L. Uso de plantas medicinais nos cuidados de saúde dos moradores de assentamento no município de Anapu, Pará, Brasil. Biodiversidade, Cuiabá, v. 16, n. 2, p. 3044, 2017.

LIMA, C. V. S.; CARDOSO JR., H. M.; LUNAS, D. A. L. A Política de Garantia de Preços Mínimos para Produtos da Sociobiodiversidade (PGPM-Bio): potencialidades da intervenção estatal para conservação ambiental em Goiás. Revista Brasileira de Desenvolvimento Territorial Sustentável, Curitiba, v. 3, n. 1, p. 37-65, 2017. DOI: http://dx.doi.org/10.5380/guaju.v3i1.51566.

LIMA, D. M. D.; TANNO, G. N.; PURCINO, M., BIASI, L. A.; ZUFFELLATO-RIBAS, K. C.; ZANETTE, F. Enraizamento de miniestacas de espinheira-santa (Maytenus ilicifolia Mart. ex Reissek) em diferentes substratos. Ciência e Agrotecnologia, Lavras, v. 33, n. 2, p. 617-623, 2009. DOI: https://doi.org/10.1590/S1413-70542009000200040.

LORENZI, H.; MATOS, F. J. A. Plantas medicinais no Brasil: nativas e exóticas. 2 ed. Nova Odessa: Instituto Plantarum, 2008. 544p.

LUEDELING, E.; KINDT, R.; HUTH, N. I.; KOENIG, K. Agroforestry systems in a changing climate - challenges in projecting future performance. Current Opinion in Environmental Sustainability, v. 6, p. 1-7, 2014. DOI: https://doi.org/10.1016/j.cosust.2013.07.013.

MABE, K.; YAMADA, M.; OGUNI, I.; TAKAHASHI, T. In vitro and in vivo activities of tea catechins against Helicobacter pylori. Antimicrobial Agents and Chemoterapy, v. 43, n .7, p. 1788-1791, 1999. DOI: 10.1128/AAC.43.7.1788.

MAGALHÃES, P. M. Agrotecnologia para o cultivo de espinheira-santa. Campinas: Centro Pluridisciplinar de Pesquisas Químicas, Biológicas e Agrícolas. 2002. [atualizado em 15 de maio de 2011]. Disponível em: http://www.cpqba.unicamp.br/plmed/artigos/agroesps ant.htm.

MAHARJAN, S. K.; GURUNG, A. R.; STHAPIT, B. R. Enhancing on-farm conservation of agro-biodiversity through community seed bank: an experience of Western Nepal. The Journal of Agricultural and Environment, v. 12, p. 132-139, 2011. DOI: 10.3126/aej.v12i0.7573.

MARIOT, M. P.; BARBIERI, R. L. Metabólitos secundários e propriedades medicinais da espinheira-santa (Maytenus ilicifolia Mart. ex Reiss. e Maytenus aquifolium Mart.). Revista Brasileira de Plantas Medicinais, Botucatu, v. 9, n. 1, p. 89-99, 2007a.
MARIOT, M. P.; BARBIERI, R. L. O Conhecimento popular associado ao uso da espinheira-santa (Maytenus ilicifolia e $M$. aquifolium). Revista Brasileira de Biociências, Porto Alegre, v. 5, n. 1, p. 666-668, 2007 b.

MARIOT, M. P.; BARBIERI, R. L.; SINIGAGLIA, C.; BENTO, L. H.; RIBEIRO, M. V. Presença do arilo na produção de mudas de Maytenus ilicifolia. Ciência Rural, Santa Maria, v. 35, n. 2, p. 468-470, 2005. DOI: http://dx.doi.org/10.1590/S0103-84782005000200038.

MARTIN, A. R.; ISSAC, M. E. Plant functional traits in agroecosystems: a blueprint for research. Journal of Applied Ecology, v. 52, n. 6, p. 1425-1435, 2015. DOI: https://doi.org/10.1111/1365-2664.12526.

MARTINELLI, S.; OLIVEIRA, A. S.; SANTOS, R. O.; WINTER, M. A.; DOLCE, A. V.; GUELLER, A. C. G. $\mathrm{V}$. Controle de qualidade da droga vegetal "espinheirasanta" encontrada em mercados de Sinop/MT. Facider Revista Científica, Colíder, v. 11, p. 1-12, 2018.

MASSON, D. O. Propagação vegetativa na produção de mudas de espinheira-santa (Maytenus ilicifolia Mart. ex Reissek). 51f. Monografia [Engenharia Florestal] - Universidade Tecnológica Federal do Paraná, Dois Vizinhos, 2017.

MATADIUA, C. A. P.; STOLF, R.; ABREU, L. S. Adoção de práticas de manejo da agrobiodiversidade e estratégias de diversificação dos meios de vida das comunidades rurais em Pirenópolis - Goiás. Revista Brasileira de Agroecologia, v. 9, n. 1, p. 134-140, 2014.

MEDEIROS, M. F. T.; SILVA, P. S.; ALBUQUERQUE, U. P. Quantification in ethnobotanical research: an overview of indices used from 1995 to 2009. Sitientibus (Série Ciências Biológicas), Feira de Santana, v. 11, n. 2, p. 211 230, 2011. DOI: $10.13102 /$ scb108.

MELO, S. F.; SOARES, S. F.; COSTA, R. F.; SILVA, C. R.; OLIVEIRA, M. B.; BEZERRA, R. J.; CALDEIRA-DEARAÚJO, A.; BERNARDO-FILHO, M. Effect of the Cymbopogum citratus, Maytenus ilicifolia and Baccharis genistelloides extracts against the stannous chloride oxidative damage in Escherichia coli. Mutation Research, v. 496 , n. $1-2$, p. 33-38, 2001. DOI: https://doi.org/10.1016/S1383-5718(01)00216-9.

MENDES, B. G.; MACHADO, M. J.; FALKENBERG, M. Triagem de glicolipídios em plantas medicinais. Revista Brasileira de Farmacognosia, Curitiba, v. 16, p. 568575, 2006. DOI: https://doi.org/10.1590/S0102695X2006000400022

MINNAERT, A. C. D. S. T.; FREITAS, M. D. C. S. Práticas de higiene em uma feira livre da cidade de Salvador (BA). Ciência \& Saúde Coletiva, Rio de Janeiro, v. 15, n. 1, p. 1607-1614, 2010. DOI: https://doi.org/10.1590/S141381232010000700072.

MONTANARI, T.; BEVILACQUA, E. Effect of Maytenus ilicifolia Mart. on pregnant mice. Contraception, Amsterdam, v. 65 , n. 2, p. 171-175, 2002. DOI: https://doi.org/10.1016/S0010-7824(01)00301-8.

MONTANARI, T.; CARVALHO, J. E.; DOLDER, H. Effect of Maytenus ilicifolia Mart. ex. Reiss. on spermatogenesis. Contraception, Amsterdam, v. 57, n. 5, p. 335-339, $1998 . \quad$ DOI: https://doi.org/10.1016/S0010-7824(98)00038-9.

MORENO, G.; AVIRON, S.; BERG, S.; CROUS-DURAN, J.; FRANCA, A.; JALÓN, S. G.; HARTEL, T.; MIRCK, J.; PANTERA, A.; PALMA, J. H. N.; PAULO, J. A.; RE, G. A.; SANNA, F.; THENAIL, C.; VARGA, A.; 
VIAUD, V.; BURGESS, P. J. Agroforestry in the European common agricultural policy. Agroforestry $\begin{array}{lll}\text { Systems, } & \text { v.92, } & \text { p.1117-1127, } 2018 .\end{array}$ https://doi.org/10.1007/s10457-018-0251-5.

MOSSI, A. J.; MAZUTTI, M.; PAROUL, N.; CORAZZA, M. L.; DARIVA, C.; CANSIAN, R. L.; OLIVEIRA, J. V. Chemical variation of tannins and triterpenes in brazilian populations of Maytenus ilicifolia Mart. Ex Reiss. Brazilian Journal of Biology, São Carlos, v. 69, n. 2, p. 339-345, 2009. DOI: https://doi.org/10.1590/S151969842009000200015.

NASCIMENTO, V. T.; LACERDA, E. U.; MELO, J. G.; LIMA, C. S. A.; AMORIM, E. L. C.; ALBUQUERQUE, U. P. Controle de qualidade de produtos à base de plantas medicinais comercializados na cidade do Recife-PE: ervadoce (Pimpinella anisum L.), quebra-pedra (Phyllanthus spp), espinheira-santa (Maytenus ilicifolia Mart.) e Camomila (Matricaria recutita L.). Revista Brasileira de Plantas Medicinais, Botucatu, v. 7, n. 3, p. 56-64, 2005.

NEGRI, M. L. S. Secagem das folhas de espinheira-santa - Maytenus ilicifolia Mart. ex Reiss. sob diferentes temperaturas e influência nos teores de polifenóis, na atividade antioxidante e nos aspectos microbiológicos. 78f. Dissertação [Mestrado em Ciências Farmacêuticas] - Universidade Federal do Paraná, Curitiba, 2007. Disponível em: https://acervodigital.ufpr.br/handle/1884/12096.

NEGRI, M. L. S.; POSSAMAI, J. C.; NAKASHIMA, T. Atividade antioxidante das folhas de espinheira-santa Maytenus ilicifolia Mart. ex Reiss., secas em diferentes temperaturas. Revista Brasileira de Farmacognosia, Curitiba, v. 19, n. 2b, p. 553-556, 2009. DOI: https://doi.org/10.1590/S0102-695X2009000400007.

NICHOLLS, C. I.; ALTIERI, M. A. Bases agroecológicas para la adaptación de la agricultura ao câmbio climático. Cuadernos de Investigación UNED, Sao Jose (CR), v. 11, n.1(esp), p. 555-561, 2019. DOI: https://doi.org/10.22458/urj.v11i1.2322.

OHSAKI, A.; NARUSE, Y. I. M.; AYABE, S. I.; KOMIYAMA, K.; TAKASHIMA, J. Four new triterpenoids from Maytenus ilicifolia. Journal of Natural Products, v. 67, n. 3, p .469-471, 2004. DOI: https://doi.org/10.1021/np030379d.

OLIVEIRA JR., C. J. F.; CAVALARI, A. A.; CARPITA, N. C.; BUCKERIDGE, M. S.; BRAGA, M. R. Cell wall polysaccharides from cell suspension cultures of the Atlantic Forest tree Rudgea jasminoides (Rubiaceae). Tree, v.24, p.713-722, $2010 . \quad$ DOI: https://doi.org/10.1007/s00468-010-0441-x.

OLIVEIRA JR., C. J. F.; CABREIRA, P. P. Sistemas agroflorestais: potencial econômico da biodiversidade vegetal a partir do conhecimento tradicional ou local. Revista Verde de Agroecologia Desenvolvimento Sustentável, Pombal, v. 7, n. 1, p. 212-224, 2012.

OLIVEIRA JR., C. J. F.; CABREIRA, P. P.; BEGOSSI, A. The dilemma of plant knowledge and compensation for native people living in brazilian biomes. Journal of Ecosystem \& Ecography, v. 2, p. 100-108, 2012. DOI: 10.4172/2157-7625.1000108.

OLIVEIRA JR., C. J. F.; VOIGTEL, S. D. S.; NICOLAU, S. A.; ARAGAKI, S. Sociobiodiversidade e agricultura familiar em Joanópolis, SP, Brasil: potencial econômico da flora local. Hoehnea, São Paulo, v. 45, n. 1, p. 40-54
2018. DOI: https://doi.org/10.1590/2236-8906$78 / 2017$.

OLIVEIRA, M. G. M.; MONTEIRO, M. G.; MACAÚBAS, C.; BARBOSA, V. P.; CARLINI, E. A. Pharmacologic and toxicologic effects of two Maytenus species in laboratory animals. Journal of Ethnopharmacology, Lausanne, v. 34, n. 1, p. 29-41, 1991. DOI: 10.1016/03788741(91)90186-h.

OLIVEIRA, R. S.; COULAUD-CUNHA, S.; COLAÇO, W. Revisão da Maytenus ilicifolia Mart. ex Reissek, Celastraceae: contribuição ao estudo das propriedades farmacológicas. Revista Brasileira de Farmacognosia, Curitiba, v. 19, n. 2b, p. 650-659, 2009. DOI: https://doi.org/10.1590/S0102-695X2009000400025.

PASTUR, G. M.; ANDRIEU, E.; IVERSON, L. R.; PERI, P. L. Agroforestry landscapes and global change: landscape ecology tools for management and conservation. Agroforestry Systems, v. 85, p. 315-315, 2012. https://doi.org/10.1007/s10457-012-9496-6.

PERLEBERG, T. D.; BARBIERI, R. L.; MARIOT, M. P.; PETER, R.; GOMES, G. C.; SILVA, T. E.; VITORIA, J. M.; SILVA, P. S.; MAGALHÃES, R. S. C. Pollinators and seed dispersers of espinheira-santa (Monteverdia ilicifolia Celastraceae), a Brazilian medicinal plant. Ciência e Natura, Santa Maria, v. 43, e52, 2021. https://doi.org/10.5902/2179460X43185.

PEREIRA, A. M. S.; JANUÁRIO, A. H.; QUEIROZ, M. E. E.; BIONDO, R.; FRANÇA, S. C. Evaluation of Maytenus aquifolium Mart. and Maytenus ilicifolia Mart. chemotypes for tannins, total phenols and triterpenes. Revista Brasileira de Plantas Medicinais, Botucatu, v. 8, n. 1, p. 13-17, 2005.

PESSUTO, M. B.; COSTA, I. C.; SOUZA, A. B.; NICOLI, F. M.; MELLO, J. C. P. Atividade antioxidante de extratos e taninos condensados das folhas de Maytenus ilicifolia Mart. ex Reiss. Química Nova, Rio de Janeiro, v. 32, n. 2, p. 416-419, 2009.

RADOMSKI, M. I.; BULL, L. T. Caracterização ecológica e fitoquímica de quatro popuklações naturais de Maytenus ilicifolia no estado do Paraná. Pesquisa Florestal Brasileira, Colombo, v. 10, n. 61, p. 1-16, 2010. DOI: 10.4336/2010.pfb.30.61.01.

RADOMSKI, M. I.; SCHEFFER, M. C.; BULL, L. T. Características fenotípicas de 44 progênies de espinheirasanta (Maytenus ilicifolia Mart. ex Reiss) cultivadas no município de Ponta Grossa, PR. Revista Brasileira de Plantas Medicinais, Botucatu, v. 10, p. 34-43, 2008.

RADOMSKI, M. I.; WISNIEWSKI, C.; CURCIO, G. R.; RACHWAL, M. G.; SANTOS, C. A. M. Caracterização de ambientes de ocorrência natural e sua influência sobre o peso específico e o teor de polifenóis totais de folhas de espinheira-santa (Maytenus ilicifolia Mart.). Revista Brasileira de Plantas Medicinais, Botucatu, v. 6, p. 3643, 2004.

RAMOS, A. S.; OLIVEIRA, G. S.; SILVA, A. M. O uso de espinheira-santa e alcaçuz no tratamento da gastrite como prática integrativa. In: Simpósio de Assistência Farmacêutica, III. Anais... 2015. São Paulo: Centro Universitário São Camilo, 2015. 3p. Disponível em: http://www.saocamilo-sp.br/novo/eventosnoticias/saf/2015/SAF007_15.pdf

ROCHA, F. A. G.; ARAÚJO, L. S. G.; LIMA, T. G. D.; SILVA, E. R.; SILVA, P. A.; GUNDIM, M. K. M.; ARAÚJO, M. F. F.; COSTA, N. D. L. Características do 
comércio informal de plantas medicinais do município de Lagoa Nova/RN. Holos, Natal, v. 5, p. 264-281, 2013. DOI: https://doi.org/10.15628/holos.2013.1344.

ROCHA, J. N.; JOHANSSON, L. A. P. S.; MIRANDA, L. V.; LOPES, G. C.; DINIZ, A.; MELLO, J. C. P.; SOUZA, J. R. P. Desenvolvimento de Maytenus ilicifolia e de seus polifenóis totais sob condição de sombreamento e poda. Revista Brasileira de Plantas Medicinais, Botucatu, v. 16, n. 3, p. 663-669, 2014. DOI: https://doi.org/10.1590/1983-084x/11_112

ROSA, S. G. T.; BARROS, I. B. I. Behaviour of Maytenus ilicifolia seeds in different periods and storage conditions. Acta Horticulture, Lovaina, v. 502, p. 249-254, 1999. Doi: https://doi.org/10.17660/ActaHortic.1999.502.40.

SANTONIERI, L.; BUSTAMONTE, P. G. Conservação ex situ e on farm de recursos genético: desafios para promover sinergias e complementaridades. Boletim Museu Emilio Goeldi (Ciências Humanas), Belém, v. 11, n. 3, p. 677-690, 2016. DOI: http://dx.doi.org/10.1590/1981.81222016000300008.

SANTOS, G. U. C. A.; FREITAS, E. A.; GOMES, L. C. A.; GOUDARD, M. J. A.; GUIMARÃES, F. G.; SILVA, B. R. G.; GOMES, J. F.; SILVA, Y. C.; GONÇALVES, P. R.; CALLADO, C. H. Identificação anatômica de amostras comercializadas como espinheira-santa na Região Metropolitana do Rio de Janeiro. Paubrasilia, Porto Seguro, v. 4, e064, 2021. DOI: https://doi.org/10.33447/paubrasilia.2021.e0064

SANTOS, V. A. F. F. M.; SANTOS, D. P.; CASTROGAMBOA, I.; ZANONI, M. V. B.; FURLAN, M. Evaluation of antioxidant capacity and synergistic associations of quinonemethide triterpenes and phenolic substances from Maytenus ilicifolia (Celastraceae). Molecules, v. 15, n. 10, p. 6956-6973, 2010. DOI: 10.3390/molecules15106956.

SATEL, R.; MARQUES, N. Influência do fitoterápico Maytenus ilicifolia na gastroproteção. Revista Brasileira de Nutrição Funcional, São Paulo, v. 28, p. 30-35, 2015.

SHIROTA, O.; MORITA H.; TAKEYA, K.; ITOKAWA, H. Cytotoxic aromatic triterpenes from Maytenus ilicifolia and Maytenus chuchubuasca. Journal of Natural Products, v. 57, n. 12 , p. 1675-1681, 1994. DOI: https://doi.org/10.1021/np50114a009.

SILVA, A. J.; COSTA, R. S.; MARIANO, A. S.; SILVA, K. L. S.; JORDÃO, C. O. Análise farmacognóstica de amostras de espinheira-santa Maytenus ilicifolia (Schrad.) Planch. (Celastraceae) comercializadas em farmácias e banca popular de Votuporanga. Revista Brasileira de Farmácia, v. 4, n. 93, p. 457-462, 2012.

SILVA, R. H.; FERREIRA JÚNIOR, W. S.; MOURA, J. M. B.; ALBUQUERQUE, U. P. The link between adaptive memory and cultural attraction: new insights for evolutionary ethnobiology. Evolutionary Biology, New York, v. 47, p. 273-284, 2020. DOI: https://doi.org/10.1007/s11692-020-09516-8.

SOARES, L. A.; OLIVEIRA, A. L.; ORTEGA, G. G.; PETROVICK, P. R. Development and validation of a LC-method for determination of catechin and epicatechin in aqueous extractives from leaves of Maytenus ilicifolia. Journal Pharmaceutical and Biomedical Analysis, v. 36, n .4, p. 787-790, 2004. DOI: https://doi.org/10.1016/j.jpba.2004.08.029.
SOUZA-FORMIGONI, M. L. O.; OLIVEIRA, M. G. M.; MONTEIRO, M. G.; SILVEIRA-FILHO, N. G.; BRAS, S.; CARLINI, E. A. Antiulcerogenic effects of two Maytenus species in laboratory animals. Journal of Ethnopharmacology, Lausanne, v. 34, n. 1, p. 21-27, 1991. DOI: https://doi.org/10.1016/03788741(91)90185-G.

STEENBOCK, W.; RADOMSKI, M. I.; SOARES, A. D. O.; PUCHALSKI, A. Avaliação de características fenotípicas para determinação de rendimento foliar em EspinheiraSanta. Revista Brasileira de Plantas Medicinais, Botucatu, v.6, n.1, p.71-76, 2003.

STEENBOCK, W.; VEZZANI, F. M.; COELHO, B. H. S.; SILVA, R. O. Agrofloresta agroecológica: por uma (re)conexão metabólica do humano com a natureza. Revista Brasileira de Desenvolvimento Rural Sustentável, Curitiba, v. 6, n. 2, 2020. DOI: http://dx.doi.org/10.5380/guaju.v6i2.76544.

TABACH, R.; OLIVEIRA, W. P. Evaluation of the antiulcerogenic activity of a dry extract of Maytenus ilicifolia Martius ex. Reiss produced by a jet spouted bed dryer. Die Pharmazie - An International Journal of Pharmaceutical Sciences, v. 58, n. 8, p. 573-576, 2003.

TEIXEIRA, D. F.; TAPPIN, M. R. R.; CARDOSO, I. C.; LUCCHETTI, L.; JACOB, S. C. Panorama da qualidade de amostras de espinheira-santa provenientes de Arranjos Produtivos Locais e do comércio do Rio de Janeiro através de métodos farmacopeicos e análise de componentes principais. Revista Virtual Química, Niterói, v. 10, n. 1, p. 194-209, 2018. DOI: 10.21577/1984-6835.20180016.

TELLO, E.; CASTILLO, E. G. Sistemas agrarios sustentables y transiciones en el metabolismo agrario: desigualdad social, cambios institucionales y transformaciones del paisaje en Catalunya (1850-2010). Halac, Anapólis, v. 2, n. 2, p. 267-306, 2013.

UDAWATTA, R. P.; RANKOTH, L. M.; JOSE, S. Agroforestry and biodiversity. Sustainability, v. 11, e2879, 2019.2 DOI: https://doi.org/10.3390/su11102879.

ULLOA-ULLOA, C.; RODRÍGUEZ, P. A.; BECK, S.; BELGRANO, M. J.; BERNAL, R.; BERRY, P. E.; et al. An integrated assessment of the vascular plant species of the Americas. Science, v. 358, p. 1614-1617, 2017. DOI: 10.1126/science.aao0398.

VELLOSA, J. C. R., KHALIL, N. M.; FORMENTON, V. A. F.; XIMENES, V. F.; FONSECA, L. M.; FURLAN, M.; BRUNETTI, I. L.; OLIVEIRA, O. M. M. F. Antioxidant activity of Maytenus ilicifolia root bark. Fitoterapia, Milano, v. 77, n. 3, p. 243-244, 2006. Doi: https://doi.org/10.1016/j.fitote.2006.02.007.

VILEGAS, J. H. Y.; LANÇAS, F. M.; CERVI, A. C. High resolution gas chromatography analysis of 'espinheira santa' (Maytenus ilicifolia and M. aquifolium): analysis of crude drug adulterations. Phytotherapy Research, London, v. 8, p. 241-244, 1994.

WOOD, S. A.; KARP, D. S.; DECLERCK, F.; KREMEN, C.; NAEEM, S. PALM, C. A. Functional traits in agriculture: agrobiodiversidade and ecosystem services. Trends in Ecology \& Evolution, Amsterdam, v. 30, n. 9 , p. $\quad$ 531-539. 2015. DOI: https://doi.org/10.1016/j.tree.2015.06.013. 